\title{
Young workers in the construction industry and initial OSH-training when entering work life
}

\author{
Kari Anne Holte and Kari Kjestveit \\ Department of Social science and business development, International Research Institute of Stavanger, \\ Box 6840, 4068 Stavanger, Norway
}

\begin{abstract}
Studies have found that young workers are at risk for injuries. The risk for accidents is high within construction, indicating that young workers may be especially vulnerable in this industry. In Norway, it is possible to enter the construction industry as a full time worker at the age of 18. The aim of this paper was to explore how young construction workers are received at their workplace with regards to OHS-training. The study was designed as a qualitative case study. Each case consisted of a young worker or apprentice $(<25$ years), a colleague, the immediate superior, the OHS manager, and a safety representative in the company. The interviews were recorded and analyzed through content analysis. The results showed that there were differences between large and small companies, where large companies had more formalized routines and systems for receiving and training young workers. These routines were however more dependent on requirements set by legislators and contractors more than by company size, since the legislation has different requirements with impact on OHS.
\end{abstract}

Keywords: young workers, occupational health and safety, construction industry, safety training, apprentices

\section{Introduction}

Many studies have found that young workers are at risk for work injuries [5,11]. Identifying risk factors for work-related injuries among young workers are therefore important. A systematic review of risk factors showed that the type of job or workplace was more important than young age in itself, where number of work hazards and perceived work overload were identified as risk factors [2]. This indicates that young workers are especially vulnerable in high risk industries. An industry where injury rates are high is the construction industry [9]. A recent study showed that for construction workers, exposure is an important explanatory factor for injuries, also when age is taken into consideration [3].

To ensure that young workers are able to meet hazards and risks in the work environment, education and training within occupational health and safety (OHS) early in the employment may be crucial, a point also noted by others $[7,10]$. Since several studies have found higher risk for work-related injuries in the first months of a new job $[1,10]$, the introduction to the workplace, and the training given at the start of the employment is important.

Also in Norway, construction is one of the industries with highest accident rates [6]. This is an industry that recruits full time workers at the age of 18 , and even earlier. Secondary education starts during the year when the students become 16. Those who choose vocational education attend school for two years, before they become apprentices for two additional years. The years at school consist of a mix of theoretical classroom teaching and practical exercises. The apprenticeship is the young students' first meeting with real life work. As will be seen later in this paper, variations in this educational structure may occur.

The aim of this paper is to explore how the transition between school and work life within construction is experienced by apprentices and young workers, as well as by their colleagues and superiors, focusing especially on OHS-training given to young workers - at their first work place.

\footnotetext{
* Corresponding author: kari.anne.holte@iris.no, +475187518
} 
Table 1. Case demographics

\begin{tabular}{|l|l|l|l|l|}
\hline Case & Age & Trade & $\begin{array}{l}\text { Company size } \\
\text { (employees) }\end{array}$ & $\begin{array}{l}\text { Number of } \\
\text { interviews }\end{array}$ \\
\hline Apprentice & 20 & Carpentry & $10-20$ & 5 \\
\hline Skilled & 22 & Shuttering & $>100$ & 5 \\
\hline Apprentice 1 ) & 23 & Carpentry & $>100$ & 4 \\
\hline Apprentice & 19 & Shuttering & $>100$ & 5 \\
\hline Apprentice & 19 & Construction machine operating & $>100$ & 5 \\
\hline Unskilled & 20 & Construction machine operating & $>100$ & 4 \\
\hline Apprentice & 22 & Surface finishing & $>100$ & 6 \\
\hline Apprentice & 18 & Scaffolding & $>100$ & 6 \\
\hline Apprentice & 22 & Plumbing/ventilation work & $10-20$ & 3 \\
\hline Apprentice & 20 & Electrical engineering & $10-20$ & 4 \\
\hline Apprentice & 19 & Plumbing/ventilation work & $10-20$ & 5 \\
\hline 1) Not within the main structure of vocational education, but with four years of apprenticeship mixed with compulsory theoretical
\end{tabular}

1) Not within the main structure of vocational education, but with four years of apprenticeship mixed with compulsory theoretical courses

2,3) With only one year of vocational education at school

\section{Method}

The study was designed as a qualitative case study. Each case consisted of a young worker or apprentice $(<25$ years $)$, a colleague, the immediate superior, the OHS- manager, and a safety deputy of the company.

In total, eleven cases were included in the study. Demographic variables for the young workers in all the 11 cases are shown in table 1, as well as information about the total number of interviews performed in each case. The cases represented seven different sized companies, and a variety of occupations. Ten cases consisted of former or present apprentices, while one case was a non-skilled worker. The cases were from 18 years old to 23 years old. Due to practical reasons, we were not able to reach all informants in all cases. Not all the small companies had a safety deputy or an OHS-manager, and in some cases this was a responsibility held by the company manager. Therefore, it varied how many informants there were additional to the young worker in each case. The cases were recruited by contacting companies within the construction industry in Rogaland county. The companies were suggested by the training offices, which are responsible for the apprentice follow-up in the companies and part of the employers' organizations. Each training office was asked to suggest five companies which together should represent various sizes. The data were gathered by qualitative interviews, using a semi-structured interview guide. The interview guide consisted of questions considering the work tasks and work organization, management, OHS training, safety culture, and accident involvement. The guide to young workers and colleagues were similar, while OHS managers and safety deputies were asked about how OHS were treated on the system level. For this study; the answer to questions with regard OHS-training and follow-up when they started their job was of special interest.

All interviews were recorded. For all the young workers / apprentices the recordings were transcribed verbatim to written text. For the colleagues, supervisors and managers and safety deputies, summaries were written. The analysis were performed by using content analysis (Kvale, 1997).

\section{Results}

\subsection{Introduction to the company}

In the start of the apprenticeship/employment the large companies ( $>50$ employees) had introductory courses, though length and form varied from an hour up to one week, consisting of e-learning and classes. In one company, OHS was one of several topics, in the two other companies specific courses addressed OHS. For two of the companies, introductory courses seemed to be an established routine. For one company these courses were recently implemented. In all the three large companies the introductory courses were given in the very beginning of the apprenticeship / employment. Two companies were subcontractors for other companies. Two of the young workers belonging to these companies, were 
required to have a safety course, before even entering the work site for the contracting company.

In the small companies, the introduction could be a meeting with the manager, giving general company information. No specific training or courses were given. OHS could be mentioned in reference to information about specific dangerous work tasks, but there were no systematic focus on OHS.

\subsection{General courses}

The three large companies in the study had their own educational department that gave courses addressing OHS. One company had established its department very recently. In these departments, workers could find courses giving them certification for using certain tools and machines, as well as other courses the company decided to give. Large companies could also provide training that are asked for: like one young worker stated about OHS-training: "... if I had felt that I needed training, they would not have had objections. They are very on to us about OHS". In one company all apprentices were obliged to stay in the educational department for a period of time. However, this was not required for newly hired unskilled workers.

The small companies did not have the opportunity to give their own courses. With one exception, all the small companies claimed to have routines for sending employees, apprentices and young workers included, at externally given courses. The courses mentioned were related to specific work tasks or tools that required certification. Instead of using external courses, one company gave its employees uncertified training at the work site, regarding tools requiring formal certification.

\subsection{Practical follow-up}

Only two companies, and both of them large, explicitly stated that apprentices were formally assigned a mentor at the work site in the very beginning of their apprenticeship. The managers and safety representatives emphasized special requirements, also regarding OHS, for those who were chosen to be mentors. The third large sized company stated an ongoing discussion about implementing formalized mentors. One of the large companies also stated that apprentices were required to take part in every second safety walkaround, which is normally conducted at the work site every week. Having mentors for new, unskilled workers were stated only in one large company. In the case of the large compa- nies, The foremen still stated they arranged for the unskilled workers to work with experiences workers in the beginning.

In the large companies, there were discrepancies between what was formalized, and what was experienced by the apprentices regarding the mentors. Two apprentices stated that they were not given a mentor in a company were they according to foremen and managers should have, and one apprentice claimed having a mentor in a company which did not refer to such formalization It therefore seems that mentorship is perceived different at various levels in the organization.

None of the small companies had formal mentors. However, they all stated that new workers were obliged to work together with experienced workers. It was not required that these experienced workers should have any special focus on OHS. However, one manager was very conscious with whom he set the young workers. He said: It is crucial who they work with. You see, they have the inch rule in the same pocket as the journeyman, they eat the same chocolate, and if the journeyman smokes, the apprentices start to smoke too. (...) There is something here about being an example, both for good and bad". The citation points to a manager's opinion about the ability and qualifications needed to be a good teacher, a point also emphasized by most of the young workers.

Regardless of company size, practical training was acknowledged as an important part of the introduction. Working with an experienced colleague was seen as an important way of training, especially regarded the development of practical skills and understanding the complexity of the work situation.

\section{Discussion}

This is a case study were the results are based on 11 cases of young workers in 7 different sized companies. The results do therefore not allow for generalization. However, they may point to certain aspects of relevance for the introduction and OHStraining given to young workers at the start of their work career.

The main finding in this study is that large companies have formalized systems and structures for receiving apprentices and new workers, where OHS training and courses are implemented, though with various form and length. In small companies, including young workers into practical work is the main 
focus, without any specific focus on education in general or OHS-training. To fulfill external requirements, small companies do however send workers to externally held courses, through which small companies fulfill legal obligations.

The differences between large and small companies may be more caused by differences in contextual reality than the company size as such, where both legislation as well as requirements from contractors has impact. A Danish review points to basic requirements that has to be met in the organization of OHS activities, like management systems, safety committees and safety representatives [8]. In the case of Norway, enterprises with less than 20 employees are not required to have safety committees, while companies with less than ten employees can make agreements on not having safety representatives. The differences found between large and small companies in receiving new workers may therefore be due to general differences in existing management systems. All the large companies in this study had well established management systems, like OHS managers, safety committees and a number of safety representatives, which increased the general focus on OHS. It is likely to believe that this has implications on how young workers are introduced.

The small companies in this study, due to their company size, did not have the same requirements for safety management systems as the large companies. This may be one reason why the formal focus on OHS in the introduction for young workers was limited. The Danish study suggested that small companies may have larger problems with establishing an occupational health and safety management system with committees, safety representative and risk assessment [8]. Since the small companies in our study have between 10 and 20 employees, we can assume that their OHS-systems are less settled than for large companies, also related to an anticipation that some of these companies might be expanding. On the other hand do we also see that when the legislation requires certain actions, this is fulfilled, also in small companies (e.g. send their employees to courses when required). Therefore, a possible intervention towards safer inclusion of young workers may be to give the companies specific requirements for OHS-training for new/young workers to ensure that all young workers get such training at the start of the working carrier, also the unskilled ones. Another intervention could be to establish standards for the use of mentors, both by requiring mentors for all apprentices and new, young workers, and by es- tablishing a joint education and certification for such mentors.

In this study we found specified safety training for workers that worked for subcontractors. Construction companies that are in a supplier chain will be influenced by their contractors, due to specific safety requirements in the contracts. This may positively impact the subcontractors' OHS in general and on the safety training given to young workers and other employees that are involved with the contractors.

The review by Hasle and Limborg [8] pointed to that a lacking OHS-focus could be related to a poor OHS-culture, and personal values and priorities of the owner. One of the small companies in our study had neither any safety training nor did they ensure that certified training on certain tools was given. This may be due to cultural aspects, which is in accordance with the researchers' impression of a bad OHS-culture in the visited company. Small companies with lacking or unstable OHS-systems should be of special concern when considering the introduction of young workers, because of the dependence on individual opinions and group culture influencing the young worker.

Considering the actual training given in the large companies, the study did not go into the content of OHS-training neither by detailed questions, nor by any kind of document studies. Several studies have pointed to the importance of content and form of such training $[7,10]$. A recent review of effectiveness of OHS training showed effects of training on behavior, but for effects of training on knowledge, attitudes and health the findings was inconclusive [4]. The study also found inconclusive evidence of differences in effects between high engagement training and low engagement training (ibid). The authors pointed to the needs for more high quality research on OHS-training (ibid). We will also suggest that research on OHS-training specifically for young workers is addressed since this group of workers has special challenges, due to their lack of work experience.

Our study included several disciplines within construction. These disciplines meet different requirements, both related to certification on various tools and performing specific work tasks, as well as their position in the supplier chain. Future studies should isolate the disciplines to increase the knowledge on the requirements' impact on the OHS focus in the companies within each discipline. This will also increase the ability to design efficient interventions towards young workers. 
Finally, the methodological shortcomings should be addressed. We have earlier mentioned that the study include 11 cases. They represent 7 companies, where 3 companies have more than 100 employees and 4 companies have between 10 and 20 employees. Companies between 20 and 100 employees may therefore receive young workers in other ways than found in this study. Selection effects may also be present. The companies were selected trough lists of companies within different disciplines, given to the researchers group by the training offices. The young workers were recruited by the researchers without any information about the different companies. Nevertheless, each company could deny taking part, and we assume that those companies with a certain focus on OHS, would be more positive to participate. For small companies it could therefore be argued that our findings may be more positive than what is actually the case.

\section{References}

[1] C. Breslin and P Smith. Trial by fire: a multivariate examination of the relation between job tenure and work injuries. Occup Environ Med 63: (2006) 27-32.

[2] C. Breslin, D Day, E Irvin, S Bhattacharayya, J Clarke, A Wang. Systematic review of risk factors for work injury among youth. Institute of work and health. Toronto, 2006.
[3] K Kjestveit, JE Tharaldsen and KA Holte, Young and strong? What influences injury rates within building and construction? Safety Science Monitor 2 (2011).

[4] L. Robson, C Stephenson, Schulte P, Amick B, Chan S, Bielecky A, Wang A, Heidotting T, Irvin E, Eggerth D, Peters, R, Clarke J, Cullen K, Boldt L, Rotunda C, Grubb P. A systematic review of the effectiveness of training \& education for the protection of workers. Institute of work and health. Toronto, National Institute of Occupational Safety and Health, Cincinatti. 2010.

[5] M. Laberge and E Ledoux, Occupational health and safety issues affecting young workers: a literature review, Work 39 (2011) 215-232.

[6] Norwegian Labour Autority www.arbeidstilsynet.no/artikkel.html?tid=221885.

7] P Chin, C Deluca, C Poth, I Chadwick, N Hutchinson, and H Munby, Enabling youth to advocate for workplace safety, Safety Science 48 (2010) 570-579.

[8] P Hasle and HJ Limborg, A review of the literature on preventive occupational health and safety activities in small enterprises, Industrial Health 44 (2006) 6-12.

[9] P. Kines, LP Andersen, S Spangenberg, KL Mikkelsen, J Dyreborg and D Zohar. Improving construction site safety through leader-based verbal safety communication, Journal of Safety Research 41 (2010) 399-406.

[10] P Smith and CA Mustard, How many employees received safety training during their first year of a new job?, Injury prevention 13 (2007)37-41.

[11] S Salminen, Have young workers more injuries than older ones? An international literature review Journal of Safety Research 35 (2004) 513-521.

[12] $\mathrm{S}$ Kvale. InterView. En introduktion til det kvalitative forskningsinterview. Hans Reitzels Forlag, København.1999. 